\title{
Interactive research: concepts, contributions and challenges
}

Interactive research

\author{
Per-Erik Ellström \\ Department of Behavioural Sciences and Learning, Linköping University, \\ Linköping, Sweden and \\ Helix Competence Centre, Linköping University, Linköping, Sweden \\ Mattias Elg \\ Department of Management and Engineering, Linköping University, \\ Linköping, Sweden and \\ Helix Competence Centre, Linköping University, Linköping, Sweden \\ Andreas Wallo \\ Department of Behavioural Sciences and Learning, Linköping University, \\ Linköping, Sweden and \\ Helix Competence Centre, Linköping University, Linköping, Sweden \\ Martina Berglund \\ Department of Management and Engineering, Linköping University, \\ Linköping, Sweden and \\ Helix Competence Centre, Linköping University, Linköping, Sweden, and \\ Henrik Kock \\ Department of Behavioural Sciences and Learning, Linköping University, \\ Linköping, Sweden and \\ Helix Competence Centre, Linköping University, Linköping, Sweden
}

\begin{abstract}
Purpose - This paper introduces interactive research as an emerging approach within a broad family of collaborative research approaches in management and organization research. Interactive research is a way to contribute to the dual tasks of long-term theory development and innovation and change processes in organizations. One of the distinguishing features of interactive research is a focus on continuous joint learning processes between the researchers and the involved practitioners.

Design/methodology/approach - The basic concepts, contributions and challenges of the interactive research approach are presented and illustrated in the present paper through a practical case, the HELIX Centre.

Findings - Interactive research is a way to advance scientific knowledge about the development of new types of work organizations and the development of sustainable operations. The multi-disciplinary and interactive research approach at HELIX has made it possible to reach a high degree of both rigour and relevance in research questions and projects. The authors identified five principles from the HELIX case that were instrumental in accomplishing the dual tasks of interactive research.

Originality/value - The interactive research approach is a powerful method of collaboration between different stakeholders throughout the research process. This type of research makes it possible to interact at various levels of research, from the programme level, to research and development projects, to the individual

(C) Per-Erik Ellström, Mattias Elg, Andreas Wallo, Martina Berglund and Henrik Kock. Published by Emerald Publishing Limited. This article is published under the Creative Commons Attribution (CC BY 4.0) licence. Anyone may reproduce, distribute, translate and create derivative works of this article (for both commercial and non-commercial purposes), subject to full attribution to the original publication and authors. The full terms of this licence may be seen at http://creativecommons.org/licences/by/4.0/ legalcode
\end{abstract}

Received 13 September 2018 Revised 3 April 2019 24 August 2019

23 February 2020 22 April 2020

Accepted 13 July 2020

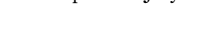


level. The results from interactive research should not only be considered traditionally valid but also valid in relation to organizational and societal needs.

Keywords Interactive research, Collaborative research, Organization development, Partnership, Learning and knowledge creation, Research intermediary

Paper type Research paper

\section{Introduction}

Organizations at present are affected by challenges such as increased globalization, digitalization and changing demographics. For manufacturing, these challenges are manifested in areas such as shortened lead times, the introduction of new technology and servitization. Thus, there is a strong demand to increase innovativeness and productivity in several domains. However, many organizations find it challenging to create sustainable systems and processes that meet these new demands (Elg et al., 2015).

Parallel to these developments, there is a growing interest in increased collaboration between universities and industry and in developing new and effective ways of using research-based knowledge to support competitiveness, regional development and innovation (Etzkowitz and Klofsten, 2005). This trend can particularly be understood against the backdrop of concerns that traditional academic research has lost its position in supporting practical problem-solving in organizations (Van de Ven and Johnson, 2006). Researchers have been criticized for putting too much focus on academic research with only a little interest in addressing practical social problems (Hodgkinson, 2001). Alvesson et al. (2017) take this critique one step further and claim that what we see is the rise of nonsense in academic research. On the other hand, practitioners, especially in professional domains, have been criticized for not using research-based knowledge for practical decision-making (Nutley et al., 2007).

One possible way to meet the challenges caused by the aforementioned changes is to find ways to bridge the gap between research and practice through increased collaboration between different stakeholders in the research process (Etzkowitz and Leyesdorff, 2000; Gibbons et al., 1994; Van de Ven, 2007). As assumed in this paper, the gap between research and practice can be understood and managed mainly as a knowledge production problem, that is, as a social-organizational problem regarding how we organize and conduct research. A general argument throughout the paper is that interactive research has a "built-in" focus on the dual tasks of contributing both to long-term theory development and to innovation and change processes in organizations.

The purpose of the paper is to introduce and conceptualize interactive research as an emerging approach within the broad family of collaborative research approaches (e.g. Shani et al., 2008). As used here the notion of collaborative research is seen as an umbrella concept including a wide range of variants, including action research, action science and participative action research. In common with several other members of the collaborative research family, interactive research is based on collaboration between researchers and practitioners throughout the research process. That is, from the definition of a problem, through data collection and analysis, to feedback and implementation of results. In the remainder of this paper, we elaborate on these aspects of interactive research, but also outline some of the distinctive characteristics of interactive research relative to other collaborative approaches. Specifically, we focus on interactive research as a way to advance scientific knowledge about the development of new types of work organizations and the development of sustainable operations. We argue to the effect that interactive research is a research approach assumed to be well suited for dealing with complex organizational phenomena (cf. Van de Ven, 2007) and at the same time for shortening the time interval from research to the practical application of the results. 
The argumentation in the paper is based on conceptualizations and reflections on our own experiences from organizing and carrying out interactive research within the framework of three consecutive research centres over a period of nearly 25 years from the mid-nineties until now. Thus, the paper has the character of a conceptual, longitudinal case study rather than a systematic review of research with the ambition of discussing different collaborative research approaches. However, the paper addresses several generic questions that are likely to arise in the conduct of an interactive research programme/project, thereby claiming a certain analytical generality. Examples of questions that will be addressed include the following: What are the relations between researchers and practitioners? How can research projects be organized from an interactive research approach? What kind of impact and utilization of knowledge might be expected from interactive research? We will deal with these and other issues in an explorative and open way based on reflexive interpretation (Alvesson and Sköldberg, 2017) without attempting to propose a set of prescriptive principles for design and implementation of interactive research.

The rest of the paper is structured as follows. In the following two sections, we first describe the origin of the interactive research approach as an attempt to find a third way between mainstream, linear forms of research (e.g. the R\&D model) and action research. This is followed by some methodological considerations and a presentation of a model for joint knowledge creation between researchers and practitioners. Next, we present a research centre, the HELIX Centre, to exemplify how one may organize for and carry out interactive research in practice. Finally, we propose ways in which interactive research may support sustainable working life development and discuss some challenges and limitations associated with this form of collaborative research. Thus, our focus will mainly be on the programme level of research and how one may conceive and organize interactive research processes. It is important to emphasize that the ambition is not to promote an interactive research approach as the single best approach for all types of research problems or contexts. Rather, the main idea behind this paper is to illustrate what interactive research could mean in practice and to discuss the pros and cons of using such a research approach.

A main contribution of the paper is the conceptualization and operationalization of interactive research as an approach that has proved successful to bridge the gap between research and practice through increased collaboration between different stakeholders in the research process. Although we do not argue that we have been able to define the precise boundaries and success conditions of the interactive research approach, we will, based on our experiences from the HELIX programme, present some operational characteristics of the interactive research approach together with a few tentative working principles for carrying out successful interactive research projects. Furthermore, we elaborate on a number of conclusions concerning issues of validity, the role of the researcher and the importance of supporting social-organizational conditions (an infrastructure) for interactive research.

\section{The interactive research approach}

The interactive research approach has its roots in a long tradition of the criticism of mainstream research models and a corresponding interest in different models of practiceoriented and collaborative research, including different versions of action research and participatory research. Thus, the interactive research approach can be viewed as one member of the larger family of collaborative research approaches (Ellström, 2008). Other research approaches that are in many respects related to interactive research as discussed here include the notion of praxis research as discussed by Sandberg (1982), the idea of Mode 2 research (Gibbons et al., 1994) and engaged scholarship as advocated by Van de Ven (2007) and Van de Ven and Johnson (2006). As members of the larger family of collaborative research
Interactive research 
approaches, these approaches have of course a number of similarities as well as differences, but to deal with these in any detail is outside the scope of the present paper.

\section{Origin of the notion of interactive research}

Interactive research is a relatively new research approach that is still quite sparsely used outside a Scandinavian context. However, it is worth noticing that the origin of the notion of interactive research as used here can be traced back to an international research conference on interactive social science in 1999 and a series of papers from this conference published in a special issue of Science and Public Policy by Caswill and Shove (2000). In a Scandinavian context, interactive research was probably first used by Lundin and Wirdenius (1990), although in a somewhat different sense than the one proposed here. As we understand and use the notion of interactive research, this approach represents an alternative - a "third way" - between mainstream, more linear models of research and different models of action research. In fact, and as further developed, the notion of interactive research as used here emerged and has largely been defined as a critique of how action research was understood and practised in the Scandinavian context around the turn of the century (Svensson et al., 2007).

Interactive research as understood in this paper is defined as a collaborative research approach characterized by recurrent interactions and joint learning activities between researchers and practitioners in commonly agreed upon efforts to study change and innovation in organizations. As further elaborated, we argue that involving different stakeholders in the research process is a way to increase the validity of research results, to shorten the time from research to practical application and to increase the probability for a sustainable impact of the research results in the participating organizations (Svensson et al., 2007; Van de Ven, 2007). In particular, a unique feature of interactive research as we understand and use the concept is a strong emphasis on joint learning activities between researchers and practitioners compared to other similar approaches, combined with a strong emphasis on traditional knowledge interests (e.g. theory development).

It is important to emphasize from the outset that the concept of interactive research should be understood as an approach towards designing the whole research process rather than as a specific set of research methods or techniques. Thus, in this sense interactive research as described here can be viewed as a "macro design" rather than a more specific design for data collection and analysis in relation to a particular research problem or set of problems ("micro design"). Therefore, an interactive research approach can be applied with a number of different research questions and types of studies ranging from descriptive-analytical studies to different types of evaluation or follow-up studies and to studies based on different forms of interventions (Van de Ven, 2007). Each of these different types of study has its own design requirements, has its ways of dealing with methodological issues (e.g. validity) and can of course also employ a wide range of methods (e.g. questionnaires, interviews or focus groups). Therefore, interactive research should essentially be considered a social-organizational mode of knowledge production at the same level of analysis as, for example, the distinction between Mode 1 and Mode 2 (Gibbons et al., 1994) or the well-known R\&D model for technology development and innovation.

\section{Distinguishing between interactive research and action research}

Before we describe in more detail how we understand the notion of interactive research, it is necessary to clarify the distinction between interactive research and certain forms of action research. Although the interactive research approach has several common roots with action research, the two approaches also differ in some important respects (for more elaborate discussions on this issue, the reader is referred to Ellström, 2008; Sandberg and Wallo, 2013; 
Svensson et al., 2007). First, contrary to classical forms of action research (e.g. Seashore, 1976), interactive research focusses less on the researcher's role in and responsibility for leading and organizing practical problem-solving or development work in organizations and instead focusses on creating opportunities for researchers and practitioners to engage in joint learning and knowledge creation. In action research, the objective of creating change often tends to take precedence over the interest in producing general and critical knowledge. This can be illustrated by a citation from Heron and Reason (2001), who argue that action research compared to "traditional" research means a shift in emphasis "from the traditional emphasis on propositional knowledge and the written word to practical knowledge and the manifest deed" (p. 184).

In line with this position, a great deal of action research approaches tends to sacrifice traditional research interests (e.g. theory development) for a kind of "practicism". Thus, as noted decades ago by Seashore (1976), action research often risks becoming a justification for practical development work that masquerades as research and, conversely, for research being reduced to a consultancy role (e.g. some kind of action learning or change management effort). In contrast, the aim of interactive research is to conduct critical analyses of the research object (e.g. an organizational change project) to contribute both to long-term theory development (e.g. new concepts or models) and to the practical needs of the participants (e.g. continuous improvements of ongoing change projects). Of course, this dual task implies a number of tensions and dilemmas related to the inescapable trade-offs between the aims and interests of research and those of practice - tensions and dilemmas that we will return to in the following section.

Second, although interactive research has the ambition of conducting research with the participants during the entire research process - from the definition of the problem to the dissemination of the results (Svensson et al., 2015) - there is at the same time an emphasis on the importance of a clear division of labour between researchers and practitioners. The researchers and participants simply have different roles and perform different tasks within the common framework of an interactive research process based on different knowledge interests, responsibilities and competencies. These differences partly have their roots in cultural differences between the two spheres of research and practice (e.g. differences with respect to autonomy). Of course, the co-operation and division of labour between researchers and practitioners are likely to bring to the fore a number of problems concerning authority, power and participation, which need to be carefully analysed and taken into account in the planning and execution of research. In addition, there are important ethical issues that need to be addressed. To establish a mutually acceptable ethical framework, it is necessary to discuss and establish a consensus concerning the values and goals underlying the research effort, the methods to be used and the expected outcomes of the research at the outset of the research process.

\section{A note on methodology}

What then are the methodological implications of the co-operation between researchers and practitioners? As argued earlier, the interactive research approach is consistent with the use of different types of studies and research methods with different strengths and weaknesses from a research quality perspective. By implication, issues concerning quality or possible tensions between relevance and rigor in interactive research need to be resolved differently depending on the purpose of research, type of study, the research methods that are used and so on (cf. Van de Ven, 2007).

At a general level, however, it is rather well established that the relationship between researchers and subjects affects the outcomes of research (Argyris, 1980; Eikeland, 2006; Rosenthal, 1966). Concerning the more specific question of in what way a co-operative
Interactive research 
relationship between researchers and practitioners affects the reliability and validity of research data, there is little or no direct evidence. There exists, however, rather general assumptions about such effects. These assumptions range from those that emphasize co-operation as a threat to the objectivity and validity of research to those that stress the importance of co-operation for gaining access to organizational processes and obtaining valid data. However, taken together, available methodological analyses seem to indicate that collaborative and practice-oriented forms of research - when used under favourable conditions and competently implemented - are not inferior to mainstream research with respect to the validity of the research results (Argyris, 1980; Eikeland, 2006). Indeed, research quality and practical relevance might turn out to be in many instances complementary rather than conflicting. In line with this, there are studies that report a positive relationship between academic quality and practical relevance (Baldridge et al., 2004; Van de Ven, 2007).

However, although important to the advancement of interactive research, these methodological and epistemological issues are beyond the scope of the present paper and will not be further addressed here (for discussions of these issues, the interested reader is referred to, e.g. Aagaard and Svensson, 2006 and Svensson et al., 2015).

\section{A conceptual model of interactive research}

The conceptual model for interactive research that has been used in our research (see Figure 1) has, as mentioned earlier, been developed on the basis of many years of experience based on different forms of collaborative research (Ellström et al., 1999; Svensson et al., 2007, 2015) and in interplay with practical work to organize and manage the HELIX Centre as presented in the next section. As illustrated in Figure 1, the conceptual model includes two interacting organizational systems, namely the research system and the practice system. The basic activities in both systems, that is, research activities and different kinds of organizational problem-solving activities and actions, are assumed to be informed by explicit ("scientific") or implicit ("local") theories based on previous research and/or practical experience. The activities are somewhat simplified, depicted as cyclical in character and driven by problems/issues originating in research or practice.

Furthermore, a basic point in this model, as indicated by the shaded circle in the intersection between the two systems, is that the process of interactive research is assumed to

Figure 1.

Interactive research as a two-way flow of problems and knowledge (Svensson et al., 2015, p. 352)

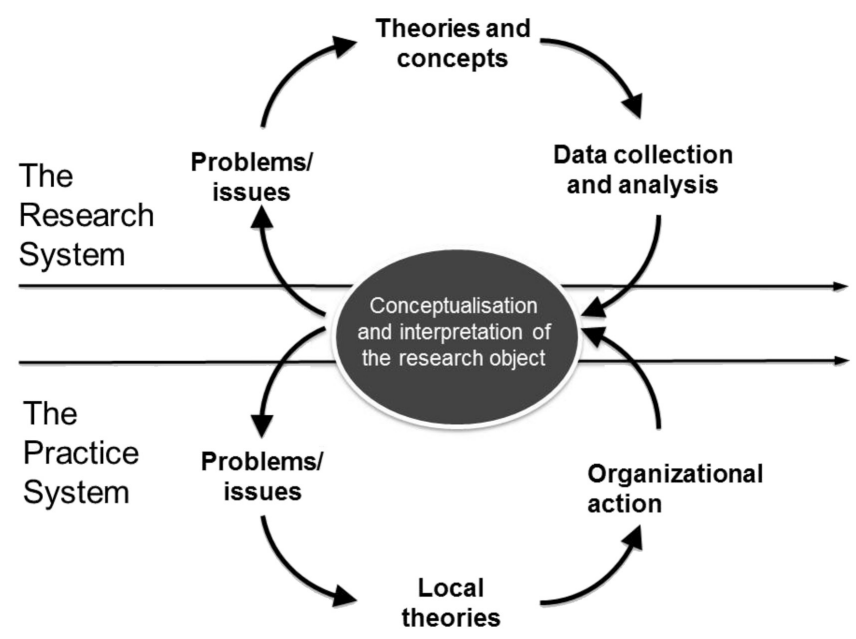


produce - ideally - common conceptualizations and interpretations of the research object (e.g. an ongoing change process) that are fed back as "cognitive inputs" into the next cycle of practical problem-solving activities and into the next cycle of research activities. Thus, these cyclical processes of knowledge creation are conceived of as two interlocked, collective learning cycles that - over time (as indicated by the two arrows representing a time axis) generate successive and hopefully more knowledgeable ways of conceptualizing and understanding the research object. The model is interactive in the sense that it attempts to organize a two-way flow of problems and knowledge. In this way, it is possible to obtain more or less continuous access to ongoing change processes in an organization (in real time or in retrospect; cf. Van de Ven, 2007) and to radically shorten the time that usually passes between research and the practical application of results. Borrowing a notion from Eikeland (2013), we can talk about two symbiotic learning systems with the potential to contribute both to effective learning and the implementation of knowledge and to conceptual and theoretical development.

\section{Co-production of knowledge}

The conceptual model for interactive research starts with a joint process of diagnosis and problem finding, where the researchers and practitioners together try to conceptualize and define the problems and issues that should be addressed, that is, a common research object. This problem-finding process may sometimes require an empirical study of the problem area ("a pilot study") to define the research object and the problems to address. Thus, as argued by Van de Ven and Johnson (2006), the practice system (e.g. an organization) is viewed not primarily as a site for data collection but as a site for an ongoing process of idea generation and learning in which researchers and practitioners co-produce and test alternative ideas of a common research object.

As the research is carried out, the degree of interactivity typically varies between projects and within projects over time. It is thus more or less unavoidable that, at any single moment in the research process, either research or practice takes precedence over the other. By implication, action- and learning-oriented activities are allowed to predominate during certain periods of time, while more research-oriented activities are allowed to predominate during others. As argued by Eikeland (2006), it is useful to make a distinction between "on-stage performance" at the workplace, that is, activities related to data collection or learning activities and "back-stage reflections", with a focus on analysis and critical reflection (Eikeland, 2006, p. 232). An alternation between these two phases is assumed to be fruitful from the perspective of the validity of research results and from the practical perspectives of organizational learning and change.

\section{Analytic seminars as temporary arenas for knowledge integration}

However, it is equally important to connect and "bridge" the "on-stage" and the "back-stage" phases. It is only through these "bridges" that it is possible to organize the processes of joint learning and knowledge creation that are essential to interactive research. The aim of these joint learning processes - or processes of collaborative inquiry (Argyris, 1980) - is to explore problematic situations or puzzling research findings to test and examine different assumptions, make discoveries and generate new knowledge that is of interest and value from both a theoretical and a practical perspective (Svensson et al., 2015). An important tool for this process of inquiry (depicted by the shaded circle in the middle of Figure 1) is the organization of collaborative analytic seminars, where researchers and relevant participants meet to jointly analyse and discuss research findings and where - ideally - new interpretations and conceptualizations of the research object are generated. Competently arranged and carried out, these analytic seminars become an arena for encounters and
Interactive research

$\longrightarrow$


dialogues between researchers arguing and presenting data from an essentially outsidespectator perspective based on a "detached", theory- and research-based view of the research object and an insider-participant perspective based on the subjective experiences and practicebased knowledge of the actors (e.g. managers, workers) in the practice system.

Considered in this way, analytic seminars have the potential to integrate research-based and practice-based knowledge through joint critical reflection between researchers and participants. As argued by Aagaard and Svensson (2006), it is thereby possible to move beyond the specific here-and-now circumstances of current work practices by broadening the views of the situation at hand, providing unexpected perspectives and presenting new opportunities for action. Thus, this type of analytic seminar may trigger developmental (creative) learning and practice-based innovations that challenge established routines and ways of thinking and acting that are taken for granted (Ellström, 2010; Jensen et al., 2007; March, 1991).

This interactive view of knowledge creation and learning can be contrasted with the common assumption made by traditional, linear models of research that there are predefined practical problems that are waiting to be solved by research and that the solutions can then be disseminated to potential users. Although this assumption may be true in a few cases, you usually cannot expect to find workable solutions to predefined practical problems in such a linear fashion and without an interactive process of inquiry. Rather, most significant realworld problems tend to be too complex and fuzzy to be captured by any one actor or perspective (Caswill and Shove, 2000; Van de Ven and Johnson, 2006). Instead, the problems typically have to be analysed, redefined and handled through interactive processes between researchers and practitioners.

\section{Organizing interactive research - the case of the HELIX Centre}

The interactive research approach presented in this paper was developed over a period of 25 years in three consecutive centres at Linköping University, Sweden (1994-2005, 2006-2015, 2017-ongoing). The more specific description presented further is based on the second of these centres. The HELIX Centre has its own economy, and its premises are centrally located within the campus area. Formally, the HELIX Centre has an administrative link to a so-called "host department" within the university.

The centre gathers more than 30 researchers from different disciplines and partner organizations. The disciplines represented are behavioural sciences, management, business and public administration, entrepreneurship and innovation and health and work sciences. This multi-disciplinary organization is one of the cornerstones of the centre. Another cornerstone is the partnership approach to organizing stakeholders. Therefore, universities and private firms as well as actors within the public sector, the labour market and civil society organizations are actively engaged in research and development activities. The partnership has made it possible to establish HELIX as an active intermediary between different interests and actors. The role as an intermediary means in practice that we are able both to create and transfer relevant knowledge to our partner organizations and to a broader range of national actors in the innovation system.

The centre focusses on integrated knowledge production, synthesis and utilization across five research areas or so-called clusters. These clusters are assumed to represent important conditions and driving forces for sustainable development in organizations: production and organization development; learning for change and innovation; health, competence and work ability; new forms of organization; entrepreneurship and innovation.

The centre is led by a board of directors and a centre director. The management structure of the centre also includes a management team, a research and innovation council, a national advisory board and an international scientific board. 
The primary task of the organization and management of the centre is to create conditions that facilitate the successful implementation of its vision, goals and strategy. Such conditions include effective communication, co-operation and learning among the parties involved. Broad participation by the members of a partnership in the research and innovation process is necessary. Further each function is briefly described (see Figure 2).

The partnership has an ownership function/role in the centre, including decision-making about the research and innovation programme. The partnership, in combination with the interactive research model, has been of importance for the HELIX research programme. The partners provide access to workplaces, are involved in the process of generating research questions and projects and participate in feedback seminars. The partnership can be described from this viewpoint as an arena for inter-organizational learning, where different actors participate in mutual learning activities.

The board represents the members of the partnership. The composition of the board is crucial since its main task is, in co-operation with the centre director, to take an active role in decisions about projects and budgets based on the formal rules of procedure in line with the centre's vision, goals and strategy.

The centre management team, comprising the centre director, two co-directors and a centre coordinator/communications officer, implements decisions made by the board, prepares for and follows up on meetings with the board, in the research and innovation council and in partnership meetings. Important tasks include planning and co-ordinating conferences, seminars, the management of the centre's dissemination activities and other activities.

The research and innovation council, led by the centre director, is an arena for discussing ongoing projects, testing new project ideas, developing research and innovation activities and supporting the integration of knowledge. The council meets once a month and comprises the seven researchers from the HELIX research group.

The HELIX research programme concentrates on development processes in organizations (e.g. production and organization development, competence development, health promotion) with a focus on conditions and driving forces for sustainable development. The core meaning of sustainable development is about achieving long-term effects of development work (and interventions) in organizations without consuming more resources (human, social, material) than those generated or regenerated. In the five mentioned research clusters, the
Interactive research

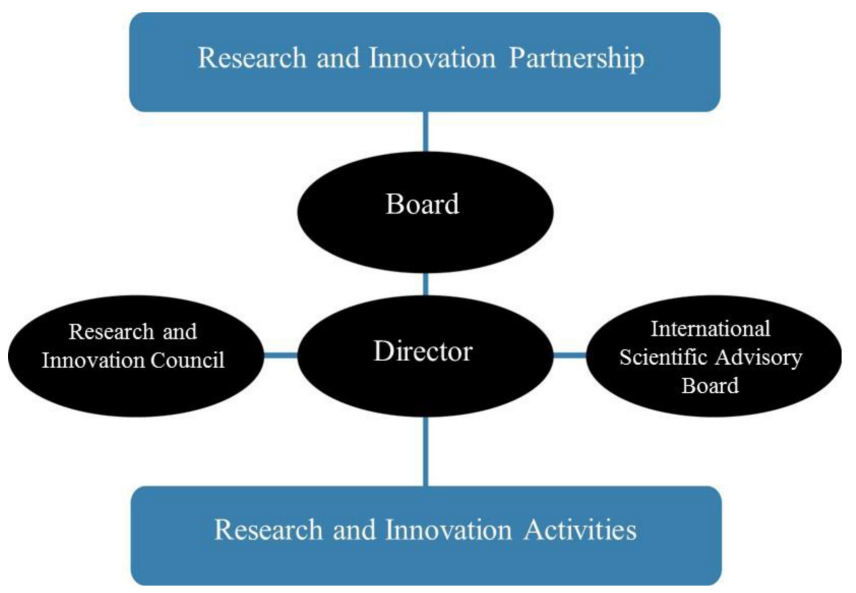

Figure 2. An organization scheme of the HELIX competence centre 
common overall research question concerns how to understand and manage sustainable development in companies and public sector organizations.

The research in HELIX has resulted in a large number of publications presented in international journals, conference papers, books and reports. A summary of the volume and patterns of the centre's scientific publications during the years of 2011-2015 is presented in Table 1. In addition, HELIX has produced $26 \mathrm{PhD}$ theses and hundreds of conference articles and reports.

The focus on sustainable development is directed towards both theory development and knowledge utilization among the partners of the HELIX Centre. In the next section, we elaborate on the various forms of the use of knowledge and the potential impact that may result from interactive research designs.

\section{Designing research for knowledge utilization and long-term impact}

The practical impact of working-life studies is long term and not easily measured. In the HELIX research programme, three main types of research use and practical impact have been distinguished:

(1) Direct or instrumental use, where research results are used more or less directly as inputs or guidelines for policy action or the development of new products, processes (e.g. organizational changes) or services and, thus, in this sense, are linked to concrete actions (or decisions).

(2) Indirect or conceptual use, which means that research results, even if they cannot be linked to concrete actions or decisions, can have indirect impacts, for example, by providing new concepts, ideas or perspectives that might provide an increased understanding of a certain process, programme or activity, its strengths, weaknesses and unintended consequences; by providing ideas for improvements or more radical changes of products or processes; and by building competence in certain areas.

(3) Process-related use, that is, uses that are related to participating in a research process rather than just from the research results. The idea is that participating and interacting with others in projects or a programme may lead to uses and impacts in a broader sense. For example, individuals may gain opportunities for learning, the exchange of ideas, networking or building new coalitions that can be significant in relation to business initiatives, recruitment and so on. Organizations may also gain credibility or status by engaging in a research partnership.

Considering empirical research on knowledge utilization in the past, a recurrent finding is that different forms of the direct use of research results appear to be much less common than indirect forms of knowledge utilization (for an overview, see, e.g. Nutley et al., 2007). Research evidence also indicates a range of barriers to reaching direct and instrumental forms of knowledge use. What seems to be needed to overcome these barriers is a broader view of knowledge transfer and innovation processes that presupposes learning and competence

Table 1.

Volume and patterns of publication

\begin{tabular}{lrrrrrr}
\hline & & \multicolumn{5}{c}{ Year } \\
Type of publication & 2011 & 2012 & 2013 & 2014 & 2015 & Total \\
\hline Articles & 25 & 40 & 40 & 33 & 42 & 180 \\
Books & 2 & 4 & 3 & 6 & 8 & 23 \\
Chapters in books & 14 & 17 & 19 & 28 & 25 & 103 \\
Total & 41 & 61 & 62 & 67 & 75 & 306 \\
\hline
\end{tabular}


building among users of research. Thus, to be able to implement research results, a potential user needs to learn to actively interpret and translate the results to fit the specific needs and challenges in the local context. Another implication is that an organization's capacity to use research is likely to improve over time through individual and collective learning, for example, learning through participation in relevant research projects and through interaction with researchers.

In the case of HELIX, most partners report clear benefits from the research collaboration. For many partners, participation in the centre also means increased interaction with the university and, therefore, significantly increased access to research-based knowledge. In a survey, more than half of the partners reported direct, instrumental benefits, and almost three-quarters of the partners reported different forms of indirect impacts (see Elg et al., 2016, Impact Evaluation Report - HELIX VINN Excellence Centre Year, 2006-2015).

In the following section, we provide three different examples of the direct, indirect and process-related uses and impacts of research results.

\section{Leadership and management at Rimaster}

The first example is the collaboration with the company Rimaster $\mathrm{AB}$, which is a leading developer and manufacturer of wiring harnesses, battery cables, electrical cabinetry, electronics, cabs, control panels and mechanics. The company started in the 1980s in Rimforsa, which is south of Linköping in Sweden, but has now developed into the Rimaster Group with approximately 1,000 employees. Currently, Rimaster operates globally with units for sales, development and production in Sweden, Poland, China, Belgium, France and Germany. The research collaboration has been ongoing since 2005 and centres around two major projects. The first project, "Leadership for workplace learning", focusses on how firstline managers work with competence and learning issues in practice and the meaning of managerial support for learning at work (Wallo, 2008). The second project, "Coordinating management", focusses on coordination, communication and collective learning in Rimaster's top management team (Wallo et al., 2012). Common to both projects is the use of the interactive research approach, which is characterized by dialogue with company representatives during the whole process from the choice of research objects and the formulation of research problems to the discussion and dissemination of the results. In both projects, there has also been a strong emphasis on activities for learning and knowledge use: project definition seminars, joint analysis seminars, result and implementation seminars. According to the $\mathrm{CEO}$ of Rimaster, the two projects have contributed to several important results:

(1) The introduction of common guiding principles for leadership and managerial work, the development and implementation of informal leadership seminars for first-line managers and a leadership training programme;

(2) The development and implementation of a new HR strategy and ongoing efforts to integrate this strategy with the overall business strategy;

(3) New perspectives on and knowledge about leadership and managerial work among first-line managers and senior managers.

From a research perspective, the interactive research in collaboration with Rimaster has resulted in the development of a theory of learning-oriented leadership, which is being developed into a scale intended for further research. The interactive research has also resulted in one $\mathrm{PhD}$ and a number of research publications intended for both international and national audiences.
Interactive research 
This second example concerns the HELIX role in developing a Swedish model for lean production, both in the industry and in the public sector. In a programme called "The Production Lift", which was started in 2006 and is still operating, some 300 SMEs have participated in the programme. The aim of The Production Lift programme is to strengthen Swedish manufacturing companies' competitiveness by offering subsidized university education through on-site coaching to increase the productivity and innovation capacities of participating companies. The programme stipulates that a minimum of two managers or lean coordinators from each company must participate in a university course (7.5 ECT credits). The support from coaches is ongoing for 18 months, and the coaching is based on lean principals, such as standardized processes, continuous improvements and justin-time (JIT) principles (see also Halvarsson Lundqvist and Gustavsson, 2018). HELIX has been assigned as interactive researchers in the evaluation and development of the programme. The collaboration has been based on a learning and ongoing evaluation approach. From a research perspective, interactive collaboration with The Production Lift programme has been very valuable. In terms of publications, the collaboration has resulted in two dissertations, five scientific articles and several chapters in three books. The interactive collaboration has also provided valuable theoretical contributions to an increased understanding of how a learning evaluation approach can be conducted, its strengths and its limitations. From a practice perspective, HELIX was important in several ways. The evaluation showed a need to strengthen the collaboration between the Swedish Metal Workers Union (IF Metall) and the Confederation of Swedish Enterprises (Svenskt Näringsliv) as well as a need to increase and broaden the collaboration with the universities providing the university course. The Production Lift programme has been very important for the participating companies and is still (after more than ten years) in progress with new companies. The programme has also inspired the development of a similar programme targeting public organizations, namely "The Operations Lift", which operated between 2009 and 2017. In the establishment of this programme for public organizations, HELIX played a major role in starting the programme, providing learning evaluations and participating in the steering committee of the programme.

\section{Development of a diary-based method for patient co-creation}

The third example concerns co-creation with patients in healthcare delivery. Together with healthcare professionals, researchers from HELIX initiated discussions about how to increase knowledge about patient processes. The practical problem was related to the problem of how to grasp experiences from the patient's perspective and how to embed this information in quality improvement initiatives. From a theoretical point of view, the initiative was motivated by the needs of developing conceptual knowledge about the co-creation of healthcare services with particular interests in the recently growing theoretical field of service-dominant logic. Through an interactive process in which healthcare practitioners and researchers from HELIX worked together, a diary-based method for understanding the patient's life, practices and experiences was developed. The starting point for the process was, thus, mutual interests in the phenomena but from different angles. The project team of practitioners and researchers continued to work together in the research design, data collection and analysis phases. The method was designed and tested in a study of 60 patients from an orthopaedic care process, a rehabilitation care process and a gastroenterology process in two hospitals (Elg et al. (2011)). The first paper was co-written with practitioners from the healthcare organization. For the practitioners, it was important to find a method that suited their needs for embedding the diary-based method in improvement programmes, and for researchers, it was important to collect information about patient experiences for the purpose of 
theoretically understanding co-creation concepts and mechanisms for patient creativity. From a practical perspective, three different ways of learning from patients increase the understanding of the various aspects that make up patients' lives and the ideas they propose for improving healthcare service delivery. Based on the findings, we suggested the diary-based method with three learning modes as a method that explicitly connects patients' co-creation and learning (Elg et al., 2012). The use of the diary method opens a new window in which it is possible to understand how patients may use their unique knowledge and resources for value creation, both for individual use and for others. The method has been subsequently further developed and applied in several development projects in Sweden and internationally. The work has also led to two PhDs and approximately ten publications providing theoretical contributions about patient co-creation. The interactive process of mutual interests in investigating conceptual and practical problems led to successful project results.

The three presented examples illustrate the possibilities for different types of utilization of knowledge and impacts within interactive research projects. Additionally, the three examples indicate that there are several challenges that researchers striving for both high-quality research and practice development need to take into account.

\section{Five working principles of the HELIX interactive research approach}

To summarize, the HELIX Centre was designed from its start to carry out research that could contribute significantly to scientific knowledge and, at the same time, add value to practice through knowledge utilization and long-term impacts to partners and society at large. More specifically, the following five principles have consciously been built into the design of the HELIX Centre, assuming that they would be instrumental in facilitating the accomplishment of the dual tasks of our interactive research approach:

(1) A partnership approach-The partner organizations' active participation in and joint ownership of the HELIX programme are assumed to be of vital importance for identifying research needs and objects, for carrying out projects and for facilitating the absorption and use of research results. Of central importance is anchoring the research at different levels of the partner organizations. Interaction needs to be carried out with both higher-level officials and employees at operational levels. A partnership of organizations also has the potential to create impacts on the research findings beyond the specific organizations that participate in a certain project.

(2) An intermediary function - Through the development of the HELIX partnership, we have been able to establish HELIX as an active intermediary between different interests and actors (Wallo and Kock, 2018). This role means, first, that HELIX is as an attractive meeting place for its partners. Second, HELIX has had a mediator role (a broker role) linking, for example, companies with the university or actors at the local, regional, national and international levels. Third, HELIX developed over time into a driver of change and innovation in partner organizations. Thus, HELIX, as an active intermediary, has the tripartite function of meeting place, mediator and motor (Smedlund, 2006).

(3) A multi-disciplinary approach - Through the multi-disciplinary basis of the research programme, it has been possible to initiate a portfolio of projects that can meet and satisfy a broad spectrum of research ideas and innovation interests among the partners and, in some cases, integrate the ideas and interests of several partners within individual larger projects. In this way, the multi-disciplinary approach has been instrumental in reaching a high degree of relevance of the research in relation to the interests and challenges experienced by the partners.
Interactive research

$\longrightarrow$


(4) An alternation between research-and practice-oriented activities over time - As noted and discussed earlier, the dual tasks of contributing both to long-term theory development and to renewal processes in partner organizations unavoidably create different tensions and may threaten the possibility of reaching a productive win-win relationship between research and practice. To handle this situation, it has in practice proved necessary to use the strategy of allowing for the alternation of and interplay between research-oriented and practice-oriented activities over time. Thus, while practice-oriented activities are allowed to predominate during certain periods of time, more purely research-oriented activities (e.g. analyses of data, writing research reports) must be allowed to predominate during others (for a theoretical interpretation of this strategy, see Eikeland, 2006).

(5) A focus on learning - The interactive research approach emphasizes joint learning and knowledge development between researchers and participants from partner organizations. Therefore, another central element in the HELIX approach was to arrange opportunities for individual and collective learning through different types of learning activities. Examples of such activities include state-of-the-art knowledge review seminars, project definition seminars, joint analysis seminars and result and implementation seminars. HELIX has also arranged university courses with a specific focus on issues of relevance to HELIX partners as well as open seminars and conferences.

In the next and final section, we discuss some challenges and limitations of the interactive research approach.

\section{Discussion}

The purpose of this paper was to conceptualize a notion of interactive research positioned as a third way between mainstream ("traditional") organizational research and different forms of action-oriented research. Traditional forms of research have been criticized for objectifying the participants, for being too specialized and for being of little practical relevance. Action-oriented research, on the other hand, has been criticized for focussing too much on issues of practice and for maximizing the contribution to practice at the expense of scientific contributions. As described in this paper, we have conceptualized and applied an idea of interactive research that combines elements of traditional research and action research. Thus, interactive research, as we conceive it, has the ambition to take on the dual tasks of contributing both to long-term theory development and to practical matters related to development and innovation in organizations.

Although the HELIX research group has been able to receive funding for developing and practising an interactive research approach over a relatively long time period (nearly 25 years), the principles and practices described in this paper should be considered tentative and in need of future corroboration in different contexts and under different conditions. Therefore, there are a number of factors that specifically need to be considered in future work to advance the interactive research approach. We will briefly comment on some of these factors further.

\section{Issues of validity in interactive research}

An obvious challenge for interactive research is to clarify and strengthen its methodological basis, especially with respect to issues of validity, that is, how we should understand and define scientific validity in relation to interactive research and the dual tasks. As argued earlier, as well as elsewhere (e.g. Svensson et al., 2015), it is essential not to give up traditional 
validity requirements because interactive researchers use the same methods as other researchers (e.g. observation, interviews, questionnaires), and validity is also important from the perspective of getting acceptance for results and publications in the broader scientific community. However, considering the dual tasks, it is also important to argue for an expanded notion of validity that takes into account the extent to which research has an impact on participating organizations and society at large. One possible candidate to include in such an expanded notion of validity is the concept of pragmatic validity (Worren et al., 2002). Partly inspired by research in cognitive ergonomics, these authors argue for a concept of validity that encompasses criteria that are relevant not only for propositional knowledge (e.g. prescriptions) but also for narrative and visual modes of knowledge. Possible criteria for judging pragmatic validity would then include the degree of adoption and impact of the proposed models and other products of research as well as the extent to which they are helpful in guiding actions to attain desired goals (Worren et al., 2002). An additional important criterion would, as described earlier, be whether the research results "pass the test" of critical joint analytic seminars where the researchers and concerned partners with different knowledge interests and perspectives analyse and discuss alternative interpretations of the research findings.

\section{The role of the researcher}

Another important challenge concerns the role of the researcher. How and to what extent should interactive researchers engage in organizational actions and processes of change (Sandberg and Wallo, 2013)? In many ways, interactive research is more complex in comparison to traditional approaches since the interactive researcher must partake in a development process without becoming captive to it (Svensson et al., 2007). As argued earlier, the collaboration between researchers and practitioners is likely to bring to the fore a number of problems concerning authority, power and participation, which need to be carefully analysed and taken into account in conducting the research. In addition, there are important ethical issues that need to be addressed. Are ethical considerations in the field underestimated at the expense of research and development interests? Is it possible to establish a mutually trusting relationship with practitioners without the risk of "going native"? Questions such as these must naturally be discussed within an interactive research project, but for the researcher, it is also crucial to allow for continuous collegial scrutiny in the academic community. According to our experience from the HELIX research programme, it is necessary - early in the research process - to discuss and establish a consensus concerning the values and goals underlying the research effort, the methods to be used and the expected outcomes of the research at the outset of the research process.

\section{Is the price for a high level of relevance too high?}

An interactive approach is typically more time-consuming than "traditional" research and thus generates relatively higher transaction costs. These costs, of course, make it necessary to weigh and value whether the increased access and the higher level of relevance to our partner organizations are worth the price when considering the higher transaction costs. Furthermore, research productivity in terms of the number of publications per year may need to be weighed against the relevance and impact of the research for partner organizations and society at large. We argue that the latter is of equal importance and is ensured by the ongoing validation attained through partnership interactions. Perhaps interactive research is not the best option for researchers with other values in this respect. Beyond these issues of valuation, there is also an obvious risk that time-consuming practical activities in the conduct of interactive research are given priority over more long-term, theory-oriented activities (Adler et al., 2004). According to our experiences, an important means for avoiding such an
Interactive research

$\longrightarrow$


outcome is that research projects and the problems to be approached are founded on an explicit theoretical framework and based on results from previous research and ongoing debate in the problem area.

\section{The importance of supporting social-organizational conditions}

A recurrent and utterly important issue concerns the exchange between researchers and participating organizations and the necessity to establish, as far as possible, mutually trusting relationships. As emphasized earlier, interactive research is not consultancy. Interactive research requires active partner organizations willing and able to be challenged by researchers, to openly share and discuss problems in their organizations and to see these problems from new perspectives. A lesson learned from the HELIX-programme is that building a partnership with the required mutual trust is a long-term process. At times, partner organizations prefer a delivery of solutions. Again, interactive research projects may not be for everyone - researchers and partner organizations alike. However, overall, we have also learned that, when the partner organizations have had a high degree of joint ownership of the projects, this process is facilitated. The joint learning process is also facilitated when there are one or more enthusiasts or "idea champions" within the organization who can promote a project or a new idea. Furthermore, and equally important, is the need not to anchor a project only or primarily at the middle level of an organization. Rather, it is important to obtain support for a project both from senior managers and from employees and their representatives within the organization. By implication, successful interactive research assumes a certain extent of mutual trust and co-operation between management and other actors (e.g. unions) in the company. Without this mutual trust, it is doubtful if an application of this approach will be successful or even possible to carry out in a specific case.

\section{Conclusions and implications}

Most mainstream research approaches - even in so-called applied research areas - do not consciously focus on issues of application and research utilization as part of the research process. The context of application and the issue of knowledge use are generally viewed as external to the research process and of little or no concern to the researcher. The main focus of traditional research is on issues of the reliability and internal validity of the research results. Therefore, there is often only limited concern about the external validity (generalizability) of the results and even less (or no) concern about pragmatic validity, that is, validity related to the practical impact and actual use of the research results. Of course, this lack of focus on the use of research results is more likely to lead to an under-utilization or even non-use of the results from mainstream research.

In contrast, interactive research as outlined in this paper places a strong emphasis on how to bridge and shorten the gap between research and practice. The relationship between research and practice is conceived as internal rather than external in the sense that researchers and practitioners collaborate in understanding and possibly changing a common research object (see Figure 1). The research object becomes a common point of departure for identifying and defining research questions and may ideally function as a boundary object (Wenger, 1998) that links the two communities of research and practice. An important implication of this approach is that interactive research, rather than considering the participating organization and its representatives as the objects of the research, fundamentally seeks to establish a subject-to-subject relationship between the researchersubject and the participant-subject with a common knowledge interest in a negotiated and agreed-upon research object (e.g. an ongoing change process). This implication also gives meaning to the idea that interactive research is carried out with rather than on participants. 
At the same time, a common research object ideally becomes the (missing) link and the boundary object between research and practice.

An important implication of this result is that the interactive research process cannot be conceived of as a pure analytical-intellectual process of knowledge creation and use but needs to be considered intimately linked to social-organizational aspects of research. Indeed, social-organizational conditions (e.g. equitable relationships between researchers and participants) that facilitate critical inquiry and developmental learning (Ellström, 2010) may be seen as necessary conditions for the validity of the research results (in the broad sense of the notion of validity used here). Therefore, we have from the start of HELIX strived to develop the HELIX partnership into a temporary organization for collective inquiry and mutual learning - between researchers, between researchers and practitioners and between practitioners from different sectors and organizations (e.g. representatives of companies, public sector organizations and unions). We also have indications that we, to some extent, have succeeded in this ambition and have established the partnership as a multi-disciplinary, information-rich arena for communication, learning and building effective working relationships between researchers and participants. Over time, the partnership has also been an important arena for identifying scientifically and practically relevant research objects and questions and for initiating research projects.

Although we consider the interactive research approach as outlined in this paper to be a potentially fruitful way to bridge the gap between research and practice, we do not claim that an interactive approach is realistic or appropriate for all types of research problems or all types of situations. In contrast, we need more knowledge about contingencies that are likely to facilitate or hinder the use of an interactive research approach. As described earlier, our experiences thus far point to a number of preconditions for the successful use of an interactive approach. However, the significance of these and other factors for conducting interactive research projects needs to be further explored.

This paper has added to previous studies of collaborative and interactive research in at least three respects. First, by arguing for the importance of an extended view of validity in interactive research, that is, what we earlier called pragmatic validity (cf. Worren et al., 2002). This concept of validity encompasses criteria that are relevant not only for propositional knowledge, but also for the degree of practical impact of proposed models and other research results as well as the extent to which they are helpful in guiding actions to attain desired goals in the partner organizations. Second, and closely related to the first point, the importance of a clear emphasis on the social-organizational aspects of research and specifically on creating arenas (e.g. analytic seminars) for collective inquiry and mutual learning between researchers and different stakeholder groups. Third, by emphasizing issues related to the "macro design" of interactive research projects, that is, the process from the initial choice of research object and definition of research questions, to data collection and analysis, to the dissemination and implementation of research findings. At the same time, issues related to "micro design", including methods for interacting with practitioners in the analysis, interpretation and conceptualization of data (e.g. during so-called analytic seminars), have been considered to be outside the main focus of this paper and have therefore not been addressed in depth. Although the present paper is limited in this respect, these issues are certainly important for the further development of the methodology of interactive research.

\section{References}

Aagaard, K. and Svensson, L. (Eds) (2006), Action and Interactive Research: Beyond Practice and Theory, Shaker Publishing, Maastricht.
Interactive research 
Adler, N., Shani, A.B. and Styhre, A. (Eds) (2004), Collaborative Research in Organizations: Foundations for Learning, Change, and Theoretical Development, Sage Publications, Thousand Oaks, CA.

Alvesson, M. and Sköldberg, K. (2017), Reflexive Methodology: New Vistas for Qualitative Research, Sage, London.

Alvesson, M., Gabriel, Y. and Paulsen, R. (2017), Return to Meaning: A Social Science with Something to Say, Oxford University Press, Oxford.

Argyris, C. (1980), Inner Contradictions of Rigorous Research, Academic Press, San Diego, CA.

Baldridge, D.C., Floyd, S.W. and Markóczy, L. (2004), "Are managers from Mars and academicians from Venus? Toward an understanding of the relationship between academic quality and practical relevance", Strategic Management Journal, Vol. 25 No. 11, pp. 1063-1074.

Caswill, C. and Shove, E. (2000), "Introducing interactive social science", Science and Public Policy, Vol. 27 No. 3, pp. 154-157.

Eikeland, O. (2006), "The validity of action research - validity in action research", in Aagaard, K. and Svensson, L. (Eds), Action and Interactive Research. Beyond Practice and Theory, Shaker Publishing, Maastricht.

Eikeland, O. (2013), "Symbiotic learning systems: reorganizing and integrating learning efforts and responsibilities between Higher Educational Institutions (HEIs) and work places", Journal of the Knowledge Economy, Vol. 4 No. 1, pp. 98-118.

Elg, M., Witell, L., Poksinska, B., Engström, J., Dahlgaard-Park, S.M. and Kammerlind, P. (2011), "Solicited diaries as a means of involving patients in development of healthcare services", International Journal of Quality and Service Sciences, Vol. 3 No. 2, pp. 128-145.

Elg, M., Engström, J., Witell, L. and Poksinska, B. (2012), "Co-creation and learning in health-care service development”, Journal of Service Management, Vol. 23 No. 3, pp. 328-343.

Elg, M., Ellström, P.-E., Klofsten, M. and Tillmar, M. (2015), "Sustainable development in organizations", in Elg, M., Ellström, P.-E., Klofsten, M. and Tillmar, M. (Eds), Sustainable Development in Organizations: Studies on Innovative Practices, Edward Elgar Publishing, Cheltenham and Northampton, MA.

Elg, M., Ellström, P.-E., Kock, H. and Tillmar, M. (2016), Impact Evaluation Report - HELIX VINN Excellence Centre Year 2006-2015, Linköping University, Linköping.

Ellström, P.-E., Eklund, J., Kock, H., Lindström, L. and Melin, U. (1999), Knowledge Creation through Collaborative Research: An Emerging Model, CMTO, Linköping.

Ellström, P.-E. (2008), "Knowledge creation through interactive research: a learning approach", Paper Presented at the ECER Conference, September 10-12, 2008, Gothenburg.

Ellström, P.-E. (2010), "Practice-based innovation: a learning perspective", Journal of Workplace Learning, Vol. 22 Nos 1-2, pp. 27-40.

Etzkowitz, H. and Klofsten, M. (2005), "The innovating region: toward a theory of knowledge-based regional development", $R$ \& D Management, Vol. 35 No. 3, pp. 243-255.

Etzkowitz, H. and Leydesdorff, L. (2000), "The dynamics of innovation: from National Systems and 'Mode 2' to a Triple Helix of university-industry-government relations", Research Policy, Vol. 29 No. 2, pp. 109-123.

Gibbons, M., Limoges, C., Nowotny, H., Schwartzman, S., Scott, P. and Trow, M. (1994), The New Production of Knowledge, Sage, London.

Halvarsson Lundkvist, A. and Gustavsson, M. (2018), "Conditions for employee learning and innovation-interweaving competence development activities provided by a workplace development programme with everyday work activities in SMEs", Vocations and Learning, Vol. 11 No. 1, pp. 45-63. 
Heron, J. and Reason, P. (2001), “The practice of Co-operative inquiry: research 'with' rather than 'on' people”, in Reason, P. and Bradbury, H. (Eds), Handbook of Action Research. Participative Inquiry and Practice, Sage Publications, London.

Hodgkinson, G.P. (Ed.) (2001), "Facing the future: the nature and purpose of management research reassessed”, British Journal of Management, Vol. 12, Special Issue, pp. S1-S80.

Jensen, M.B., Johnson, B., Lorenz, E. and Lundvall, B.-A. (2007), "Forms of knowledge and modes of innovation”, Research Policy, Vol. 36 No. 5, pp. 680-693.

Lundin, R.A. and Wirdenius, H. (1990), "Interactive research", Scandinavian Journal of Management, Vol. 6 No. 5 , pp. 125-142.

March, J.G. (1991), "Exploration and exploitation in organizational learning”, Organization Science, Vol. 2 No. 1, pp. 71-87.

Nutley, S.M., Walter, I. and Davies, H.T. (2007), Using Evidence: How Research Can Inform Public Services, Policy press, Chicago.

Rosenthal, R. (1966), Experimenter Effects in Behavioral Research, Appleton-Century-Crofts, New York.

Sandberg, F. and Wallo, A. (2013), "The interactive researcher as a virtual participant: a Habermasian interpretation", Action Research, Vol. 11 No. 2, pp. 194-212.

Sandberg, A. (1982), "Från aktionsforskning till praxisforskning”, Sociologisk Forskning, Vol. 19 Nos 2-3, pp. 80-89.

Seashore, S.E. (1976), "The design of action research", in Clark, A.W. (Ed.), Experimenting with Organizational Life: The Action Research Approach, Plenum Publ., New York.

Shani, A.B., Mohrman, S.A., Pasmore, W.A., Stymne, B. and Adler, N. (Eds) (2008), Handbook of Collaborative Management Research, Sage Publications, Thousand Oaks, CA.

Smedlund, A. (2006), "The roles of intermediaries in a regional knowledge system", Journal of Intellectual Capital, Vol. 7 No. 2, pp. 204-220.

Svensson, L., Ellström, P.-E. and Brulin, G. (2007), "Introduction - on interactive research", International Journal of Action Research, Vol. 3 No. 3, pp. 233-249.

Svensson, L., Brulin, G. and Ellström, P.-E. (2015), "Interactive research and ongoing evaluation as joint learning processes", in Elg, M., Ellström, P.-E., Klofsten, M. and Tillmar, M. (Eds), Sustainable Development in Organizations: Studies on Innovative Practices, Elgar, Cheltenham.

Van de Ven, A. and Johnson, P.E. (2006), "Knowledge for theory and practice", Academy of Management Review, Vol. 31 No. 4, pp. 802-821.

Van de Ven, A.H. (2007), Engaged Scholarship: A Guide for Organizational and Social Research, Oxford University Press, Oxford.

Wallo, A. and Kock, H. (2018), "HR outsourcing in small and medium-sized enterprises: exploring the role of human resource intermediaries”, Personnel Review, Vol. 47 No. 5, pp. 1003-1018.

Wallo, A., Kock, H. and Nilsson, P. (2012), "Accelerating and braking in times of economic crisis: organisational learning in a top management team", European Journal of Training and Development, Vol. 36 No. 9, pp. 930-944.

Wallo, A. (2008), "The leader as a facilitator of learning at work: a study of learning-oriented leadership in two industrial firms", Doctoral dissertation, Linköping University Electronic Press, Linköping. 
Wenger, E. (1998), Communities of Practice: Learning, Meaning, and Identity, Cambridge University Press, Cambridge.

Worren, N.A., Moore, K. and Elliott, R. (2002), "When theories become tools: toward a framework for pragmatic validity”, Human Relations, Vol. 55 No. 10, pp. 1227-1250.

\section{Appendix \\ Examples of impact}

\section{Development of leadership and lean production across private and public organizations}

(1) Contributing to the development of a Swedish model for lean production, both in industry and in the public sector.

(2) Principles for leadership and managerial work in job descriptions for managers at various levels of partnership organizations, both in industry and in the public sector.

(3) Collaboration in the management development programme for managers in elderly care in private and public organizations.

\section{Development of work organizations and production processes in industry}

(1) Contribution to continuous improvement, employee involvement and production development in industry.

(2) Guidance of industry partners when reorganized in response to the economic crisis during 2008-2009.

(3) Stimulation of innovation and entrepreneurship within the life science industry, for example, the development of a new coaching module and improved guidelines for different project activities.

(4) Development and implementation of new HR strategies and ongoing efforts to integrate HR strategies with the overall business strategy of the company.

\section{Improvements and development of new models, processes and innovations in public organizations}

(1) Integration of processes for innovation support as part of the regular operations in several municipalities, for example, as part of the existing management system.

(2) New approaches and models for co-creation and learning with patients in healthcare service development that have been utilized in various healthcare environments.

(3) New strategies to improve the ability to work among long-term sick listed and young people on disability benefits in collaboration projects between the Social Insurance Agency, healthcare organizations, the Public Employment Service and municipalities.

(4) Development of a new R\&D centre in the field of human resource development and management (HRD/HRM) at Region Östergötland.

(5) Improvements to the "customer-choice model" for public procurement within elderly care. 


\section{Intermediaries' and unions' utilization and dissemination of research}

(1) Input to policy actions as well as changes in existing practices within the EU Structural Funds, for example, concerning the formulation of programme criteria, project calls and recommendations to include learning evaluations in all larger projects that are funded.

(2) Support to the union IF Metall at a regional and a national level to systematically advance the organization's knowledge in relation to employers and other actors (e.g., funders).

\section{Corresponding author}

Mattias Elg can be contacted at: Mattias.elg@liu.se

For instructions on how to order reprints of this article, please visit our website:

www.emeraldgrouppublishing.com/licensing/reprints.htm

Or contact us for further details: permissions@emeraldinsight.com 